\title{
A DESVINCULAÇÃO DAS RECEITAS DA UNIÃO (DRU) COMO INSTRUMENTO DE FLEXIBILIZAÇÃO DO ORÇAMENTO PÚBLICO NO BRASIL: NECESSIDADE OU DISTORÇÃO?
}

\author{
THE UNTYING OF UNION REVENUES AS FLEXIBILITY INSTRUMENTO OF \\ THE PUBLIC BUDGET IN BRAZIL: NEED OR DISTORTION?
}

\author{
${ }^{1}$ Francisco Gilney Bezerra de Carvalho Ferreira \\ ${ }^{2}$ Renata Albuquerque Lima
}

\section{Resumo}

O presente trabalho expõe o tema do orçamento público brasileiro e a crise na gestão das finanças públicas, percebendo o crescente anseio social em se conferir maior rigidez à peça orçamentária. Todavia, as reiteradas manobras de flexibilização do orçamento público acabam por frustrar o seu real objetivo. Neste artigo, busca-se analisar o instituto da Desvinculação das Receitas da União, tratando-se de mecanismo que busca garantir a livre alocação de receitas orçamentárias. A presente pesquisa teve como recurso metodológico o método teórico-bibliográfico, embasado através de pesquisa documental.

Palavras-Chave: orçamento público; flexibilização orçamentária; desvinculação das receitas da união.

\begin{abstract}
This paper exposes the theme of the public budget and the crisis in public finance management, realizing the growing social anxiety to be providing greater rigidity to the budget planning. However, the repeated maneuvers of the budget flexibility end up frustrating your real goal. In this article, we try to analyze the untying of budget revenues, in the case of mechanism that seeks to ensure the free allocation of revenue budget. This research had as methodological resource bibliographic theoretical method, based in documentary research.
\end{abstract}

Keywords: public budget; budget flexibility; untying of budget revenues.

\footnotetext{
1 Mestrando em Direito pela Universidade Federal de Santa Catarina, UFSC - SC, (Brasil). Especialista em Direito Público e MBA em Gestão Pública pela Faculdade Getúlio Vargas ,FGV - SP, (Brasil). Procurador Federal (AGU) e Professor do Curso de Graduação em Direito da Faculdade Luciano Feijão, Ceará - CE, (Brasil).E-mail: gilneybezerra@ hotmail.com

${ }^{2}$ Pos-doutora pela Universidade Federal de Santa Catarina, UFSC - SC, (Brasil). Doutora em Direito pela Universidade de Fortaleza, UNIFOR - CE, (Brasil). Professora da Graduação e Mestrado em Direito do Centro Universitário Christus, UNICHRISTUS , Fortaleza - CE,( Brasil). E-mail: realbuquerque @yahoo.com
} 


\section{1 - INTRODUÇÃO}

O orçamento público brasileiro vem evoluindo como instrumento de planejamento do Estado, de forma que é perceptível se observar um fenômeno de expressiva redução no grau de discricionariedade alocativa dos recursos. Atualmente, há diversas restrições no uso das receitas, tanto em decorrência das transferências constitucionais, quanto pelo aumento das vinculações obrigatórias, reduzindo-se o montante das receitas com livre disponibilidade. Contrapondo-se à tendência crescente de maior rigidez orçamentária, surge o instituto da Desvinculação de Receitas da União, a chamada "DRU", tendo novamente sua validade prorrogada, dessa vez até o exercício de 2023, conferida pela recente Emenda Constitucional $n^{\circ}$. 93/2016, com o nítido objetivo de ampliar os recursos livres da União, buscando recuperar, em parte, certa margem de liberdade do gestor.

A cada nova prorrogação da DRU, renovam-se os debates acerca da sua juridicidade e conveniência. A rigor, a discussão possui como pano de fundo uma eterna discussão no âmbito das finanças públicas: conferir maior vinculação ao orçamento com redução da discricionariedade administrativa, havendo o risco de se provocar engessamento estatal, ou abrir possibilidade para maior flexibilidade na sua aplicação, com o consequente risco de inefetividade das políticas públicas e desvio de recursos? Na verdade, existem manobras através das quais, mesmo com vinculação de parte da receita, o governo consegue diminuir a relativa rigidez orçamentária, seja ao subestimar receitas permitindo a obtenção de superávits, seja com o contingenciamento de dotações retardando a execução de despesas, seja pela transferência de despesas pelo mecanismo dos restos a pagar, ou ainda, seja pelo mecanismo da Desvinculação das Receitas da União, instituto ao qual nos propomos a analisar.

Nesse sentido, levamos a questão em discussão, desenvolvendo-a em três partes. $\mathrm{Na}$ primeira, optou-se por fazer um exame das premissas teóricas em que se fundamenta o orçamento público dentro do contemporâneo contexto do estado constitucional democrático, percebendo a correlação deste com a proteção dos direitos fundamentais. Na sequência, pontuou-se especificamente a deficiência crônica que existe no âmbito das finanças públicas, bem como a tensão existente na gestão do orçamento público no Brasil e a crise entre os poderes na efetivação do planejamento orçamentário, com a percepção dos mecanismos de flexibilização orçamentária. Por fim, analisou-se o instituto da Desvinculação das Receitas da 
União (DRU), prorrogado pela Emenda Constitucional $\mathrm{n}^{\circ} .93 / 2016$, observando as implicações no orçamento e sua compatibilidade com os demais preceitos constitucionais.

\section{2 - A MiSSÃo CONSTITUCIONAL DO ORÇAMENTO PÚBLICO NO ATUAL CONTEXTO DO ESTADO DEMOCRÁTICO DE DIREITO}

Para regular o funcionamento da sociedade e garantir o bem estar comum, é dever do Estado suprir as necessidades públicas, que se referem ao conjunto das obrigações a que se vinculou perante à sociedade, daí surgindo a necessidade do exercício de uma atividade financeira estatal, o que se faz por meio do instrumento do orçamento público, com função essencial para o equilíbrio do Estado e da sociedade ${ }^{3}$. Na verdade, desde suas origens, a noção de um orçamento público guarda estreita conexão com a necessidade de autorizar e controlar a aplicação do dinheiro público, estando relacionado ao desenvolvimento da democracia, como forma de limitação do poder estatal e desenvolvimento da democracia, tratando-se de uma espécie de delegação de poder para o dispêndio dos recursos públicos ${ }^{4}$. No seu âmago, portanto, trata-se o orçamento de espécie de pacto de confiança para que os representantes do povo possam, em seu nome, realizar o dispêndio dos recursos públicos.

Sobre a origem do orçamento público e seu papel embrionário no papel de
contenção do poder estatal, vale registrar a lição de Heleno Taveira Torres: "O
princípio de aprovação orçamentária das despesas públicas por decisão legislativa
encontra-se largamente reconhecido no constitucionalismo universal. Desconhece-se
alguma Constituição que não o contemple. Sua origem confunde-se com o
surgimento dos Estados modernos, com a separação dos poderes, com o papel do
Legislativo no controle sobre os atos dos governantes, mediante consentimento para
a aprovação, por lei, das receitas e despesas, para a consecução dos fins do Estado

3 Ensina o eminente professor Ricardo Lobo Torres: “O orçamento tem três funções precípuas: a política, a econômica e a reguladora. Devem elas ser examinadas em suas conotações com o Direito e a Constituição, eis que o corte entre os aspectos normativos e os conteúdos políticos e econômicos implica posição nitidamente positivista e formalista. Neumak indica 4 funções para o orçamento: político-financeira (racionalidade na gestão orçamentária), política (equilíbrio entre grupos políticos), de controle financeiro (do Executivo) e econômica (racionalidade da política econômica). Musgrave aponta 3 objetivos da política orçamentária: "(1) assegurar ajustamentos na alocação de recursos; (2) conseguir ajustamentos na distribuição de renda e da riqueza e (3) garantir a estabilização econômica.” (TORRES, 2008, v.5, p. 65).

4 Quanto ao orçamento público enquanto limite de poder, citamos: "Em termos políticos, a evolução histórica do orçamento público é dignitária de todos os êxitos da luta da sociedade pela democracia e controle dos poderes do Estado em matéria financeira. No Estado Constitucional, que surge a partir do final do século XIX, o orçamento ganha notável importância, não só porque sua formação coincide com a expansão das necessidades financeiras do Estado, mas porque serviria para assegurar o controle legislativo sobre a Administração. E isso porque, para o orçamento, convergem as mais importantes instituições do Estado e da Constituição, na sua permanente relação com a sociedade, quanto ao financiamento do Estado e a atuação na economia. Com o orçamento público, os povos conquistaram o direito de dominar as finanças do Estado e, ao mesmo tempo, o de controlar as escolhas democráticas, ante às preferências reveladas no processo eleitoral, no que concerne à realização contínua dos fins do Estado, da efetividade dos direitos e da apuração do cumprimento dos programas dos governantes eleitos pelo voto popular.” (TORRES, 2014, p. 342). 
(defesa, bem comum, etc.). Reminiscências da autorização legislativa para atividade financeira dos governos floresceram na Inglaterra no século XIII. Basta lembrar o compromisso da Magna Charta Libertatum, de 1215, que foi uma das primeiras fontes a evidenciar a submissão de um soberano aos direitos dos que viviam sob seu domínio [...]” (TORRES, 2014, p. 342).

Todavia, durante muito tempo a ideia do orçamento público ficou limitada a uma visão meramente contábil e formalista de receitas versus despesas orçamentárias, progredindo apenas posteriormente para o paradigma de peça fundamental programática de governo. Hoje, porém, mais que isso, além dessa originária noção sobre a qual se assenta a teoria da atividade financeira do Estado, verifica-se que, a partir do fenômeno da constitucionalização do direito ${ }^{5}$, insere-se necessariamente o orçamento público dentro de uma visão constitucional democrática, à luz da concretização dos direitos fundamentais. De fato, o orçamento público relaciona-se intimamente com a garantia dos direitos fundamentais, notadamente os direitos sociais, para fins de sua viabilização e efetivação ${ }^{6}$.

Os princípios e normas constitucionais, agora, sobrepõem-se ao restante do ordenamento, não só no plano formal, mas também material, assegurando-lhe maior força normativa $^{7}$. Obviamente, as finanças públicas e o direito financeiro não fogem à regra. Hoje, não se concebe a Constituição de outra forma senão como norma suprema, que vincula todas as demais do ordenamento, as quais devem obediência aos princípios e normas daquela. Chegamos, enfim, ao denominado Estado constitucional de direito, pautado na centralidade e supremacia da Constituição. Daí se conclui, desde logo, que o poder foi feito para os direitos fundamentais, e não o contrário, razão pela qual a escolha das prioridades públicas no dispêndio dos recursos não constitui reserva exclusiva à deliberação política ${ }^{8}$. Graças à tal

5 Sobre o tema, ensina Luís Roberto Barroso: “A ideia de constitucionalização do Direito aqui explorada está associada a um efeito expansivo das normas constitucionais, cujo conteúdo material e axiológico se irradia com força normativa por todo sistema jurídico. Os valores, os fins públicos e os comportamentos contemplados nos princípios e regras da Constituição passam a condicionar a validade e o sentido de todas as normas do direito infraconstitucional. Como intuitivo, a constitucionalização repercute sobre a atuação dos três Poderes, inclusive nas suas relações com os particulares.” (BARROSO, 2006, p. 16-17)

6 Quanto à essa íntima relação, citamos: "Os direitos fundamentais têm uma relação profunda e essencial com as finanças públicas. Dependem, para a sua integridade e defesa, da saúde e do equilíbrio da atividade financeira do Estado, ao mesmo tempo em que lhe fornecem o fundamento da legalidade e da legitimidade. Os direitos fundamentais se relacionam com os diversos aspectos das finanças públicas. Assim é que o tributo, categoria básica da receita do Estado de Direito, é o preço da liberdade, preço que o cidadão paga para ver garantidos os seus direitos e para se distanciar do Leviatã [...]” (TORRES, 2008, v.5, p. 499).

7 O reconhecimento do conteúdo normativo da Constituição teve como marco a obra do jurista alemão Konrad Hesse intitulada "A força normativa da Constituição", destacando-se a evolução do caráter jurídico (e não mais político) da Constituição. Para um aprofundamento da leitura, cf. HESSE, 1991.

8 Leciona Ana Paula Barcellos: "Se a Constituição contém normas nas quais estabeleceu fins públicos prioritários, e se tais disposições são normas jurídicas, dotadas de superioridade hierárquica e de centralidade 
mudança paradigmática, inevitavelmente, constata-se que "a validade das leis e a legitimidade da política são condicionadas ao respeito e à efetivação das garantias dos direitos estipulados nas constituições." (FERRAJOLI, 2015, p. 12).

Dessa forma, se os cidadãos, com seus recursos, financiam a atividade estatal, é mais do que obrigação do Estado, portanto, que a contrapartida seja ofertada com a concretização de políticas públicas essenciais ao povo, fazendo-se o uso responsável dos recursos públicos por meio da adequada gestão orçamentária. Logo, o dinheiro que sai do povo, é aplicado pelos seus representantes, e deve voltar por meio dos serviços públicos e investimentos sociais, com fins, em última instância, à tutela dos direitos fundamentais, os quais, vale recordar, gozam de atual hierarquia constitucional e situam-se em status elevado na ordem jurídica. Temos, dessa forma, uma necessária vinculação do poder público aos direitos fundamentais e, mais que isso, a precisa noção da missão fundamental do orçamento público nessa proteção, do que resulta uma atividade financeira estatal voltada para a consecução desse pleno objetivo.

Urge, portanto, que o orçamento público passe a ser visto dentro de uma necessária visão constitucional de instrumento fundamental do Estado (e não de governo). A propósito, segundo pronunciamento da Suprema Corte ${ }^{9}$, trata-se da lei materialmente mais importante do ordenamento jurídico logo abaixo da Constituição, não podendo ser manuseada a pretexto de interesses que não se coadunem ao seu real mister. De fato, o orçamento público, abaixo da Constituição, é o conteúdo normativo de maior importância para a continuidade do Estado ${ }^{10}$, razão pela qual se faz necessária uma abertura para a ideia do orçamento público como ferramenta constitucional fundamental do Estado na concretização dos direitos fundamentais e na garantia do princípio democrático ${ }^{11}$, visão esta que, não raro, permanece pouco difundida na comunidade jurídica e ainda não posta plenamente em prática.

no sistema, não haveria sentido em concluir que a atividade de definição das políticas públicas - que irá, ou não, realizar esses fins - deve estar totalmente infensa ao controle jurídico. Em suma: não se trata da absorção do político pelo jurídico, mas apenas da limitação do primeiro pelo segundo.” (BARCELLOS, 2005, p. 92)

9 ADI n. 4048, STF, voto do Min. Carlos Britto, Rel. Min. Gilmar Mendes, DJ. 14/05/2008.

10 Corroborando o entendimento da Suprema Corte, cf. TORRES, 2014, p. 340.

11 Valiosa a doutrina de Luigi Ferrajoli ao abordar a mudança paradigmática a partir da concepção de estado constitucional de direito como garantia à democracia material: "Esta mudança incidiu sobre a natureza das nossas democracias, tornando, a meu ver, inadequadas as tradicionais concepções puramente formais ou procedimentais da democracia enquanto conjunto de regras do jogo, independentes do (e indiferentes ao) conteúdo do jogo democrático. Isto é, de fato, introduziu na democracia uma dimensão substancial, correspondente à dimensão da validade das leis e delimitada pelos limites e vínculos jurídicos, de substância ou de conteúdo, impostos aos poderes públicos majoritários. Impôs, em resumo, o que podemos chamar de esfera do não decidível: aquilo que nenhuma maioria pode validamente decidir, isto é, a violação ou a 
[...] o que se pretende demonstrar é a urgente necessidade de constitucionalização do sistema orçamentário brasileiro. Embora as linhas gerais do processo orçamentário sejam disciplinadas na própria Constituição, sustenta-se aqui que os dispositivos constitucionais em questão têm sido interpretados de forma isolada, sem que seja levada em conta - ao menos na extensão adequada - a influência de normas constitucionais fundamentais, como os princípios da separação dos poderes e democrático. É necessário, portanto, inserir a Constituição orçamentária no contexto mais amplo da Constituição em seu conjunto. (MENDONÇA, 2010, p. 126-127)

A evidência se reforça, sobretudo, a partir da constatação de que, atualmente, os formuladores de politicas públicas são forçados a levar em consideração, inevitavelmente, variáveis externas à jurisdição e ao escopo do Estado. Matérias antes afetas à competência interna de cada Estado recebem a influência invasiva do fenômeno da globalização em um processo de internacionalização de decisões políticas ${ }^{12}$, em nítido declínio da soberania estatal e enfraquecimento do poder estatal diante de poderes transnacionais ${ }^{13}$. A intensificação de interações que ignoram as fronteiras estatais resulta, obviamente, em implicações para as politicas econômicas nacionais e reflexos, em especial, na redução das políticas sociais no orçamento do Estado ${ }^{14}$. É nesse ponto que, mais ainda, precisa ser revigorado, urgentemente, a noção do orçamento público como peça fundamental do Estado, no exercício de sua missão maior conforme os fins que lhe são constitucionalmente estabelecidos.

restrição dos direitos de liberdade, e aquilo que nenhuma maioria pode legitimamente deixar de decidir, isto é, a satisfação dos direitos sociais constitucionalmente estabelecidos.” (FERRAJOLI, 2015, p. 11).

12 "Por todos esses motivos, a 'unidade' do Estado, mais precisamente o comportamento unitário da esfera publica diante da extrema diversidade de interesses privados e do crescente numero de decisões econômicas tomadas fora do alcance de sua jurisdição funcional e de suas fronteiras territoriais, passa a ser um problema - e não um fato natural. Com o fenômeno da globalização, as estruturas institucionais, organizacionais, politicas e jurídicas forjadas desde os séculos XVII e XVIII tendem a perder tanto sua centralidade quanto sua exclusividade. No âmbito de uma economia transnacionalizada, as relações entre os problemas internacionais e os problemas internos de cada pais vão sendo progressivamente invertidas, de tal forma que os primeiros já não são mais apenas parte dos segundos; pelo contrario, os problemas internacionais não só passam a estar acima dos problemas nacionais, como também a condicioná-los." (FARIA, 1999, p. 32).

13 Quanto à transnacionalização: “A intensificação das relações sociais de emergentes sujeitos no palco externo desencadearam uma rede de interação caracterizada pelo transpasse estatal (transnacional) e não mais pela relação ponto a ponto entre os estados. Nesse contexto, marcado pela fragilização estatal de um lado e pelo reforço de outros centros de poder é que emerge a transnacionalização, evidenciada pela desterritorialização dos relacionamentos político-sociais, fomentado por sistema econômico capitalista ultravalorizado e que articula ordenamento jurídico mundial à margem das soberanias dos Estados." (STELZER, 2009, p. 15-16).

14 “....] o processo de globalização econômica subtrai dos Estados a capacidade efetiva de promover, no mundo real, os direitos humanos proclamados pelas constituições e pelas declarações internacionais. Este quadro assume contornos ainda mais dramáticos no que tange aos direitos sociais, que, por definição, pressupõem uma intervenção ativa do Estado no domínio econômico. Ora, a globalização econômica corrói os pilares do Welfare State, na medida em que reduz drasticamente o poder do Estado de implementar as políticas públicas necessárias à garantia dos direitos de $2^{\mathrm{a}}$ geração. Por outro lado, apesar de toda a evolução dos organismos supranacionais competentes, estes ainda estão muito longe do ponto em que poderão substituir o Estado, no papel de responsável primário pela promoção dos direitos sociais. Assim, cria-se um perigoso vácuo, que tende a aprofundar a miséria e injustiça social, sobretudo nos países do capitalismo periférico, como o Brasil, que são os que mais sofrem os efeitos excludentes do processo de globalização." (SARMENTO, 1999, p. 29) 
Em um panorama de rápidas transformações na estrutura do Estado e deslocamento de poder, é preciso que o orçamento público passe a ser efetivamente utilizado à luz dos mandamentos constitucionais de proteção dos direitos fundamentais. As políticas públicas recebem a influência direta das opções constitucionais que devem ser perseguidas em caráter prioritário, sob pena de comprometer a integridade da ordem constitucional, daí decorre que não se concebe a flexibilização discricionária do orçamento para fins outros que não digam respeito ao atendimento das reais necessidades sociais. Hoje, aliás, já se reconhece o direito fundamental à boa administração, do qual é devedor o Estado.

O Estado Constitucional é traduzido como Estado das escolhas administrativas legítimas e sustentáveis. Assim considerado, nele não se admite a discricionariedade irrestrita, intátil, desviante, imediatista. Em suma, impõe-se combater os recorrentes vícios de arbitrariedade por ação e por omissão. Faz-se cogente, sem desídia, enfrentar todo e qualquer "demérito" na implementação das políticas públicas, concebidas aqui como programas de Estado, mais do que de governo. Nesse desiderato, o direito fundamental à boa administração pública (conceito enunciado em debates brasileiros, sob a inspiração do art. 41 da Carta dos Direitos Fundamentais de Nice), é norma implícita (feixe de princípios e regras) de imediata eficácia em nosso sistema, a impelir o controle "lato sensu" a enfrentar a discricionariedade fora ou aquém dos limites." (FREITAS, 2014, p. 13).

O orçamento público, então, no atual contexto do estado democrático de direito, passa a sofrer sensível estreitamento em sua atuação pela incidência direta dos princípios constitucionais. Amolda-se, assim, o orçamento público como base necessária e fundamental ao Estado constitucional democrático. Dessa forma, direitos fundamentais e democracia são pilares fundamentais sobre os quais se deve pautar toda a atividade financeira do Estado ${ }^{15}$, encontrando-se este em necessária subsunção e estrita vinculação a tais mandamentos, os quais, amparados sob o manto constitucional, exercem influência decisiva na definição dos contornos da atividade estatal e, portanto, na gestão financeira do Estado ${ }^{16}$.

15 "Embora na visão contemporânea de Estado Democrático de Direito, democracia e constitucionalismo sejam vistos como valores complementares, interdependentes e até sinérgicos, a correta dosagem dos ingredientes desta fórmula é essencial para o seu sucesso. Por um lado, o constitucionalismo e limitações ao poder em demasia podem sufocar a vontade popular e frustrar a autonomia política do cidadão, como co-autor do seu destino coletivo. Por outro lado, uma 'democracia' sem limites tenderia a pôs em sério risco os direitos fundamentais das minorias, bem como outros valores essenciais, que são condições para a manutenção ao longo do tempo da própria empreitada democrática." (SARMENTO, 2006, p. 97).

16 “[...] o sistema de direitos fundamentais e o princípio democrático, tal como delineados na Constituição, exercem também influência decisiva na definição dos contornos da atividade administrativa. À centralidade desses pilares constitutivos e legitimadores da ordem constitucional deve corresponder uma igual centralidade na organização e funcionamento da Administração Pública.” (BINENBOJIM, 2014, p. 71). 


\section{3 - A TENSÃo nO ÂMbITO dAS FINANÇAS PÚbliCAS E AS MANOBRAS DE FLEXIBILIZAÇÃO NA GESTÃO DO ORÇAMENTO PÚBLICO NO BRASIL}

Considerando a necessidade de inserção do orçamento público como instrumento de Estado para a concretização dos direitos fundamentais, tem-se revelado tendência crescente, hodiernamente, o debate acerca da vinculação do poder público à peça orçamentária. Ora, se os recursos são escassos, não se pode admitir sua aplicação desordenada. A destinação precisa ser certeira, principalmente, para os fins assegurados na Carta Maior, dentre os quais estão os direitos fundamentais. Contudo, à margem de cumprir rigorosamente o orçamento, é comum ao Executivo promover inúmeras alterações na sua execução. Várias manobras acabam por frustrar a expectativa inicial estabelecida na lei orçamentária, instaurando-se uma efetiva crise no âmbito das finanças públicas no Brasil e uma constante tensão entre os poderes na esfera da gestão orçamentária. A incidência de interesses econômicos e políticos na aplicação dos recursos públicos flexibilizam preceitos constitucionais, desvirtuando o seu real objetivo.

Na prática, então, deparamo-nos rotineiramente com mecanismos de flexibilização ${ }^{17}$ adotados pelo Executivo que desvirtuam o real objetivo do orçamento. As expectativas criadas a partir da proposta orçamentária não demoram muito para serem frustradas logo em seguida, convertendo-se o orçamento em mera peça retórica. A decisão de gastar é, sem dúvida, eminentemente política, porém, também jurídica na medida em que deve necessário respeito aos ditames constitucionais. O processo de elaboração das leis orçamentárias acaba por esvaziar seu sentido quando a discricionariedade é utilizada como manobra para justificar a inexecução daquilo que foi exaustivamente planejado e discutido, sobretudo quando os recursos seriam necessários à proteção de direitos alçados à mandamento constitucional ${ }^{18}$.

Nesse contexto, fica demonstrado que além das competências inerentes ao exercício de suas atribuições intrínsecas, o sistema jurídico confere uma série de instrumentos de flexibilidade que permitem ao Executivo, durante a fase de execução orçamentária, deixar de dar cumprimento efetivo ao orçamento público da forma

17 "Na prática, os mecanismos de flexibilidade orçamentária acabam conferindo ampla margem de discricionariedade ao Poder Executivo, na medida em que permitem que as dotações orçamentárias aprovadas pelo Legislativo sejam alteradas. Assim, muito embora a previsão de tais mecanismos se faça necessária, até mesmo para o atendimento de situações imprevisíveis e urgentes, acabam, por vezes, transformando-se em um instrumento de concentração de poder [...].” (DALLAVERDE, 2013, p. 119)

18 "O sistema atual permite que as decisões políticas produzidas no processo deliberativo sejam inteiramente esvaziadas e substituídas por decisões unilaterais e imotivadas do Poder Executivo. Nesse contexto, políticas públicas relevantes - decididas pelo procedimento majoritário em sua essência - têm sido desconsideradas de forma pouco consistente, para dizer o mínimo. É certo que o controle desse quadro passa também, e talvez sobretudo, pela cidadania fiscal, mas não se deve tomar como fato da vida um sistema orçamentário que institucionaliza o referido esvaziamento." (MENDONÇA, op. cit., p. 90-91) 
como aprovado pelo Poder Legislativo, aumentando o poder do Chefe do Executivo na condução das finanças públicas do Estado. Entre os mecanismos, destacam-se a abertura de créditos adicionais, a previsão de reserva de contingência para o atendimento de despesas não previstas no orçamento e o contingenciamento de despesas, que permite ao Executivo afastar-se das disposições orçamentárias em razão da não-realização das receitas previstas. A par dos instrumentos de flexibilidade, existem outros mecanismos de que se vale o Chefe do Poder Executivo para alcançar um maior domínio no quadro da gestão financeira, mecanismos estes que, embora abarcados pelo sistema jurídico, são, no mais das vezes, utilizados de forma desvirtuada em relação às suas reais finalidades.” (DALLAVERDE, 2013, p. 10-11).

Nesse enfoque, não se aceita, portanto, o argumento genérico de insuficiência de recursos quando há como pano de fundo uma intensa ineficiência na gestão dos recursos. Não se admite seja colocada arbitrariamente na conta da sociedade, sob a alegativa de escassez de recursos, um buraco que, muitas vezes e, quase sempre, é provocado pela falta de otimização na aplicação (não racional) dos recursos. Até mesmo sob o pretexto de situações imprevisíveis e urgentes são utilizadas manobras de flexibilização que acabam se transformando em instrumento de concentração de poder ${ }^{19}$.

Nessa esteira, surge o anseio social pela mudança de paradigma com a passagem para o orçamento impositivo. Atualmente, a regra é de que o orçamento é autorizativo, salvo quando há vinculação expressa ${ }^{20}$. Na verdade, o desejo de um orçamento cada vez mais vinculado reflete, no seu íntimo, o anseio da população pela efetivação das políticas públicas, transferindo-se para a lei a confiança que não se tem nos governantes. Não é por outro motivo que, uma vez crescente o pleito de maior rigidez orçamentária, não é raro a adoção de mecanismos do governos com manobras de flexibilização, utilizadas com fins a obstar essa natural tendência. A propósito, vale registrar relevante precedente no âmbito da Suprema

19 "Obviamente, a execução da despesa depende da arrecadação da receita, mas isso não significa nem autoriza o puro e simples descumprimento do orçamento, até mesmo de forma transversa, mediante o uso indevido de medidas provisórias. Uma simples consulta à lista de medidas provisórias editada nos últimos anos serve para evidenciar a prodigalidade com a qual elas foram utilizadas para a abertura de créditos extraordinários, para atender despesas ordinárias, usuais, sem qualquer urgência, em completo desrespeito ao disposto no art. 41 da Lei 4.320/64, cujo inc. III deixa claro que tais créditos somente pode ser abertos para despesas urgentes, "em caso de guerra, comoção interna ou calamidade pública". Na prática, por meio de medidas provisórias, o Executivo desrespeita o orçamento sem qualquer reserva, preocupação ou cuidado, adotando atitudes aleatórias e empíricas ao sabor dos ventos da política.” (DALLARI, 2011, p. 325).

20 Por haver vinculação expressa em parte do orçamento quanto às despesas constitucionais obrigatórias, há quem defenda ter o orçamento não um caráter autorizativo, mas híbrido, como expõe a doutrina de Marcus Abraham: “Atualmente, podemos afirmar que o orçamento público no Brasil possui um perfil dúplice: em parte é impositivo, e em parte é autorizativo. É impositivo na parte cuja execução faz-se obrigatória (despesas constitucionais e legais), e autorizativo na parcela remanescente, passível de contingenciamento e de não execução. Assim, a nosso ver, restam superados os entendimentos que generalizavam e afirmavam ser meramente autorizativo o orçamento público no Brasil.” (ABRAHAM, 2016, p. 307). 
Corte no sentido de conferir maior imperatividade ao orçamento público, consoante decisão monocrática liminar proferida pelo Min. Luiz Fux na ADI 4.663, em que se reconheceu que "as normas orçamentárias ostentam, segundo a lição da moderna doutrina financista, a denominada força vinculante mínima, a ensejar a imposição de um dever prima facie de acatamento, ressalvada a motivação administrativa que justifique o descumprimento com amparo no postulado da razoabilidade", o que leva-nos a conclusão de que, atualmente, descabe a inexecução discricionária do orçamento público pelo administrador público ${ }^{21}$.

Os recursos públicos são limitados e há muitas necessidades sociais não atendidas. Em um ambiente como esse, fica ainda mais evidente que o orçamento é uma pauta de distribuição de todo o montante de recursos existente, mesmo que seja para a constituição de reservas. Falar em escolhas trágicas e, ao mesmo tempo, admitir que receitas sejam retiradas do processo alocativo seria manifestamente inconstitucional e imoral. O que legitima a arrecadação é o destino das verbas, não se cogitando que uma das maiores cargas tributárias do mundo seja resultado de frivolidade ou descuido governamental na hora de se estimar a necessidade do caixa estatal. Além dessa perplexidade original, a atual compreensão do orçamento permite que decisões administrativas informais e imotivadas, concentradas no Presidente da República, tenham o poder de ignorar sumariamente as decisões orçamentárias produzidas segundo o processo deliberativo parlamentar. As políticas públicas reais são definidas no orçamento. Ainda que se queira reconhecer ao administrador a faculdade de superá-las, isso deveria, no mínimo, ser acompanhada de motivação." (MENDONÇA, 2013, p. 392)

De todo modo, é certo que, na medida em que está em causa uma verdadeira opção constitucional quanto à afetação material dos recursos, também deve ser realizado um controle e aferição quanto à tomada de decisão sobre a aplicação destes, porquanto está sob a responsabilidade dos órgãos políticos e representantes do povo a definição das linhas gerais das políticas públicas e destinação prioritária dos recursos, materializados no orçamento público $^{22}$. O problema, no fundo, não é a falta de recursos - embora se reconheça tal limitação

21 "Novas vozes, inspiradas nos princípios da separação dos poderes $\left(\mathrm{CF}\right.$, art $2^{\circ}$ ), da legalidade orçamentária (CF, art. 165, caput e incs. I a III) e da democracia (CF, art. $1^{\circ}$, caput), têm apontado para a necessidade de se conferir força vinculante ao orçamento público, como forma de reduzir o incontrastável arbítrio do Poder Executivo em prol da imposição de um dever relativo - e não verdadeiramente absoluto, saliente-se - de observância das normas do orçamento anual. No limite das possibilidades das práticas constitucionais ainda vigentes no cenário nacional, impõe-se reconhecer ao menos a denominada vinculação mínima das normas orçamentárias, capaz de impor um dever prima facie de acatamento, ressalvada a motivação administrativa que justifique o descumprimento com amparo na razoabilidade.” (FUX, 2016, p. 45).

22 "Como o desenvolvimento (econômico e social em primeira linha) também não poderá dispensar um planejamento (direcionamento e coordenação) das atividades estatais, a importância de um adequado planejamento a partir das prioridades enunciadas - como o são no caso brasileiro - na Constituição, resulta enrobustecida não apenas a função estratégica no planejamento em si, mas também a necessidade de procedimentos adequados e eficientes para um planejamento seguido de efetivos resultados, bem como a imprescindibilidade de mecanismos de controle variados (sociais, políticos e jurídico-jurisdicionais) do próprio planejamento, mas acima de tudo de sua implementação. Que o controle da administração pública passa a ser também um controle voltado ao objetivo de assegurar um desenvolvimento sustentável e envolve 
econômica - mas a deficiente destinação e uso não racional dos recursos que, por óbvio, são escassos. A rigor, o debate em torno dessa temática costuma se situar na origem (liberdade de recursos), quando o foco do problema deveria estar, também, no destino (racional aplicação). Pouco importa a abundância na entrada quando não há otimização na saída. Para um orçamento sem racionalização no dispêndio de recursos, pouco importará a quantidade destes disponíveis, nunca serão suficientes para a satisfação dos anseios sociais, tendo em vista a deficiência na gestão e implementação de políticas públicas. Logo, importa mais a eficiência no uso dos recursos do que a quantidade que se dispõe. Se os recursos são escassos, longe de representar um óbice, reforça mais ainda a necessidade do seu uso responsável.

A simples margem de discricionariedade pretendida pelos gestores públicos para fins de aplicação dos recursos não é suficiente quando inexiste uma adequada aplicação desses recursos que confira segurança no atendimento dos reais fins constitucionais. No fundo, o debate quanto ao poder decisório na escolha de prioridades para fins de implementação de políticas públicas passa longe de se situar onde deveria: uma visão do orçamento enquanto concretização dos direitos fundamentais e o uso responsável dos escassos recursos públicos. Ao invés de se optar por uma efetiva reforma constitucional que se confira segurança para fins de efetividade orçamentária, manobras de flexibilidade continuam a ser sistematicamente utilizadas. É o caso, por exemplo, da Desvinculação de Receitas da União, a chamada "DRU”, com vigência anteriormente estipulada pela Emenda Constitucional n $n^{\circ}$ 68/2011 até o fim do exercício de 2015 e que, após ter sua validade expirada, nova renovação foi efetuada, dessa vez por meio da $P E C n^{\circ} 87 / 2015$, como passaremos a examinar adiante.

\section{4 - A DESVINCULAÇÃo dAS RECEITAS DA UNIÃo COMO MECANISMO DE LIVRE ALOCAÇÃO DOS RECURSOS ORÇAMENTÁRIOS}

até mesmo o controle no âmbito da discricionariedade técnica, visto que não pode servir de blindagem para ações estatais (ou mesmo privadas) em manifesto desvio de finalidade e arrepio da ordem jurídicoconstitucional, nos parece elementar, embora quanto ao como do controle, especialmente do controle jurisdicional, se possa discutir sobre os seus limites." (SARLET. 2015, p. 370) 
A Desvinculação das Receitas da União (DRU), instrumento restaurado por meio da recente Emenda Constitucional $n^{\circ}$. 93/2016, que deu nova redação ao Art. 76 do ADCT $^{23}$, trata-se de instrumento que busca garantir a livre alocação de receitas orçamentárias que se encontravam originariamente vinculadas à destinação específica, com o objetivo de ampliar os recursos livres da União, recuperando, em parte, certa margem de liberdade do gestor. De fato, o excesso de vinculações orçamentárias cresceu significativamente nos últimos anos, dificultando sobremaneira a capacidade de alocação dos recursos públicos conforme eleição livre do administrador público. Nesse sentido, a Desvinculação das Receitas da União (DRU) ingressa no planejamento orçamentário como medida do governo livrar-se parcialmente das indesejadas vinculações. O objetivo, portanto, é buscar a desafetação de receitas que a União, embora arrecade, delas não disponha livremente.

A DRU teve início com a Emenda Constitucional de Revisão $n^{\circ} 1$, de $1^{\circ}$ de março de 1994, à época da implementação do Plano Real, como medida de estabilização da economia e reserva emergencial, criando-se o Fundo Social de Emergência - FSE. Posteriormente, este foi alterado pela EC n ${ }^{\circ} 10$, de 4 de março de 1996, passando a ser denominado Fundo de Estabilização Fiscal - FEF, que vigorou até 31 de dezembro de 1999. A intenção inicial era criar um mecanismo temporário de auxílio ao Governo no período de queda da inflação,

23 Dispõe o novo Art. 76 do ADCT da CF/88, com redação dada pela EC n 93/2016, que reinstituiu a DRU:

“Art. 76. São desvinculados de órgão, fundo ou despesa, até 31 de dezembro de 2023, 30\% (trinta por cento) da arrecadação da União relativa às contribuições sociais, sem prejuízo do pagamento das despesas do Regime Geral da Previdência Social, às contribuições de intervenção no domínio econômico e às taxas, já instituídas ou que vierem a ser criadas até a referida data."

“Art. 76-A. São desvinculados de órgão, fundo ou despesa, até 31 de dezembro de 2023, 30\% (trinta por cento) das receitas dos Estados e do Distrito Federal relativas a impostos, taxas e multas, já instituídos ou que vierem a ser criados até a referida data, seus adicionais e respectivos acréscimos legais, e outras receitas correntes. Parágrafo único. Excetuam-se da desvinculação de que trata o caput: I - recursos destinados ao financiamento das ações e serviços públicos de saúde e à manutenção e desenvolvimento do ensino de que tratam, respectivamente, os incisos II e III do $\S 2^{\circ}$ do art. 198 e o art. 212 da Constituição Federal; II receitas que pertencem aos Municípios decorrentes de transferências previstas na Constituição Federal; III receitas de contribuições previdenciárias e de assistência à saúde dos servidores; IV - demais transferências obrigatórias e voluntárias entre entes da Federação com destinação especificada em lei; V - fundos instituídos pelo Poder Judiciário, pelos Tribunais de Contas, pelo Ministério Público, pelas Defensorias Públicas e pelas Procuradorias-Gerais dos Estados e do Distrito Federal."

"Art. 76-B. São desvinculados de órgão, fundo ou despesa, até 31 de dezembro de 2023, 30\% (trinta por cento) das receitas dos Municípios relativas a impostos, taxas e multas, já instituídos ou que vierem a ser criados até a referida data, seus adicionais e respectivos acréscimos legais, e outras receitas correntes. Parágrafo único. Excetuam-se da desvinculação de que trata o caput: I - recursos destinados ao financiamento das ações e serviços públicos de saúde e à manutenção e desenvolvimento do ensino de que tratam, respectivamente, os incisos II e III do $\S 2^{\circ}$ do art. 198 e o art. 212 da Constituição Federal; II receitas de contribuições previdenciárias e de assistência à saúde dos servidores; III - transferências obrigatórias e voluntárias entre entes da Federação com destinação especificada em lei; IV - fundos instituídos pelo Tribunal de Contas do Município." 
enquanto as reformas fiscais não fossem aprovadas. Todavia, o que seria meramente temporário, passou a tornar-se instrumento de governo mais duradouro. Por meio da $\mathrm{EC}^{\mathrm{o}} 27$, de 21 de março de 2000, foi então criada a Desvinculação de Receitas da União (DRU), com validade até 2004, sucedendo aqueles primeiros Fundos (FSE e FEF).

Desde então, esse instrumento vem sendo prática reiterada, renovando-se ao final de cada período por meio de novas PEC's que prorrogam sua vigência. Assim sucedeu por meio da Emenda Constitucional n ${ }^{\circ}$ 42, de 19 de dezembro de 2003, dilatando sua validade até 2007, renovada em seguida pela Emenda Constitucional n $n^{\circ}$ 56, de 20 de dezembro de 2007, com validade até 2011, e, por último, prorrogada pela Emenda Constitucional $\mathrm{n}^{\circ} 68$, de 21 de dezembro de 2011, estabelecendo o prazo de renovação da DRU até o ano de 2015. Agora, expirado o prazo de sua vigência, nova prorrogação se realiza, dessa vez por meio da Emenda Constitucional $n^{\circ} 93$, de 08 de setembro de 2016, renovando sua vigência até o ano de $2023^{24}$, com entrada em vigor na sua publicação e efeitos retroativos a partir de $1^{\circ}$ de janeiro de 2016. Podemos verificar adiante, conforme quadro ilustrativo, as inovações da EC nº 93/2016:

Quadro comparativo da PEC no 31 , de 2016 (nº 4, de 2015, na Casa de origem $)^{25}$

\begin{tabular}{|c|c|}
\hline $\begin{array}{c}\text { Constituição Federal de } 1988 \\
\text { (Ato das Disposições Constitucionais } \\
\text { Transitórias - ADCT) }\end{array}$ & $\begin{array}{l}\text { Emenda Constitucional no 93, de } 2016 \\
\text { (oriunda da Proposta de Emenda à } \\
\text { Constituição no } 31 \text {, de 2016) }\end{array}$ \\
\hline & $\begin{array}{l}\text { Art. } \mathbf{1}^{\mathbf{0}} \mathrm{O} \text { art. } 76 \text { do Ato das Disposições } \\
\text { Constitucionais Transitórias passa a vigorar } \\
\text { com a seguinte redação: }\end{array}$ \\
\hline $\begin{array}{l}\text { Art. 76. São desvinculados de órgão, fundo } \\
\text { ou despesa, até } 31 \text { de dezembro de } 2015 \text {, } \\
20 \% \text { (vinte por cento) da arrecadação da } \\
\text { União de impostos, contribuições sociais e de } \\
\text { intervenção no domínio econômico, já } \\
\text { instituídos ou que vierem a ser criados até a } \\
\text { referida data, seus adicionais e respectivos } \\
\text { acréscimos legais. }\end{array}$ & $\begin{array}{l}\text { Art. 76. São desvinculados de órgão, fundo } \\
\text { ou despesa, até } 31 \text { de dezembro de } 2023 \text {, } \\
30 \% \text { (trinta por cento) da arrecadação da } \\
\text { União relativa às contribuições sociais, sem } \\
\text { prejuízo do pagamento das despesas do } \\
\text { Regime Geral da Previdência Social, às } \\
\text { contribuições de intervenção no domínio } \\
\text { econômico e às taxas, já instituídas ou que }\end{array}$ \\
\hline
\end{tabular}

24 A EC n ${ }^{\circ}$ 93, de 2016, é oriunda da PEC n 31, de 2016, chamada PEC da DRU, fruto da aprovação da PEC $n^{\circ}$ 4, de 2015, proveniente da Câmara dos Deputados, em que tramitou com as PECs nº 87 e 112, ambas de 2015, apensadas àquela. Tendo sido encaminhadas pelo Poder Executivo ao Congresso Nacional, tendo em vista o fim da vigência da DRU em 31 de dezembro de 2015. A PEC no 31/2016, cujo primeiro signatário reporta-se ao Deputado André Figueiredo, altera o art. 76 do ADCT da CF/88 e inclui neste os arts. 76-A e 76-B. Em suma, o novo texto prolonga a DRU até o exercício de 2023, aumenta o percentual de desvinculação para 30\% e cria a Desvinculação de Receitas dos Estados, Distrito Federal e Municípios.

25 Quadro elaborado pela Coordenação de Redação Legislativa da Secretaria-Geral da Mesa do Senado Federal. Disponível em: http://legis.senado.leg.br/mateweb/arquivos/mate-pdf/194806.pdf. Acesso em 12/set/2016. 


\begin{tabular}{|c|c|}
\hline & vierem a ser criadas até a referida data. \\
\hline $\begin{array}{l}\$ 1^{\circ} \text { O disposto no caput não reduzirá a base } \\
\text { de cálculo das transferências a Estados, } \\
\text { Distrito Federal e Municípios, na forma do } \\
\$ 5^{\circ} \text { do art. } 153 \text {, do inciso I do art. } 157 \text {, dos } \\
\text { incisos I e II do art. } 158 \text { e das alíneas a, b e d } \\
\text { do inciso I e do inciso II do art. } 159 \text { da } \\
\text { Constituição Federal, nem a base de cálculo } \\
\text { das destinações a que se refere a alínea c do } \\
\text { inciso I do art. } 159 \text { da Constituição Federal. }\end{array}$ & \$1 $\mathbf{1}^{\mathbf{0}}$ (Revogado). \\
\hline $\begin{array}{l}\$ 2^{\circ} \text { Excetua-se da desvinculação de que trata } \\
\text { o caput a arrecadação da contribuição social } \\
\text { do salário-educação a que se refere o } \S 5^{\circ} \text { do } \\
\text { art. } 212 \text { da Constituição Federal. }\end{array}$ & 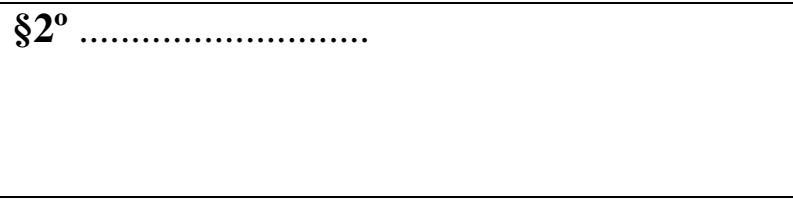 \\
\hline \multirow{3}{*}{$\begin{array}{l}\text { \$ }^{\circ} \text { Para efeito do cálculo dos recursos para } \\
\text { manutenção e desenvolvimento do ensino de } \\
\text { que trata o art. } 212 \text { da Constituição Federal, o } \\
\text { percentual referido no caput será nulo. }\end{array}$} & $\mathbf{\$ 3}^{\mathbf{0}}$ (Revogado). \\
\hline & $\begin{array}{l}\text { Art. } \quad \mathbf{2}^{\mathbf{0}} \quad \text { O } \quad \text { Ato das Disposições } \\
\text { Constitucionais Transitórias passa a vigorar } \\
\text { acrescido dos seguintes arts. 76-A e 76-B: }\end{array}$ \\
\hline & $\begin{array}{l}\text { Art. 76-A. São desvinculados de órgão, fundo } \\
\text { ou despesa, até } 31 \text { de dezembro de } 2023,30 \% \\
\text { (trinta por cento) das receitas dos Estados e } \\
\text { do Distrito Federal relativas a impostos, taxas } \\
\text { e multas, já instituídos ou que vierem a ser } \\
\text { criados até a referida data, seus adicionais e } \\
\text { respectivos acréscimos legais, e outras } \\
\text { receitas correntes. Parágrafo único. } \\
\text { Excetuam-se da desvinculação de que trata o } \\
\text { caput: I - recursos destinados ao } \\
\text { financiamento das ações e serviços públicos } \\
\text { de saúde e à manutenção e desenvolvimento } \\
\text { do ensino de que tratam, respectivamente, os } \\
\text { incisos II e III do } § 2^{\circ} \text { do art. } 198 \text { e o art. } 212 \\
\text { da Constituição Federal; II - receitas que } \\
\text { pertencem aos Municípios decorrentes de } \\
\text { transferências previstas na Constituição } \\
\text { Federal; III - receitas de contribuições } \\
\text { previdenciárias e de assistência à saúde dos } \\
\text { servidores; IV - demais transferências } \\
\text { obrigatórias e voluntárias entre entes da } \\
\text { Federação com destinação especificada em } \\
\text { lei; V - fundos instituídos pelo Poder } \\
\text { Judiciário, pelos Tribunais de Contas, pelo }\end{array}$ \\
\hline
\end{tabular}




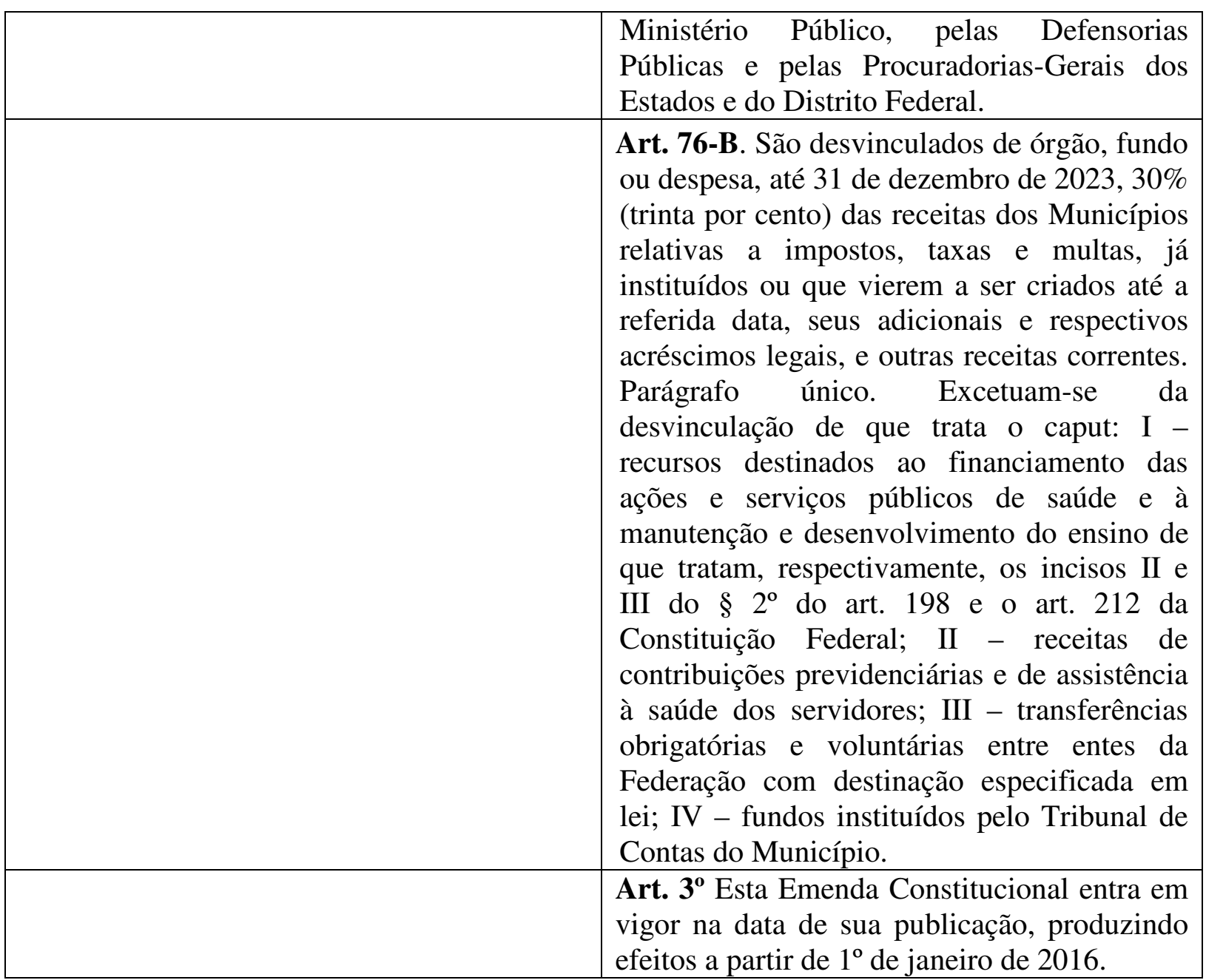

A partir do quadro comparativo acima, vale salientar algumas relevantes alterações produzidas no instituto da DRU a partir da sua nova prorrogação, conforme texto da Emenda Constitucional $n^{\circ}$ 93/2016, no sentido de ampliar, do ponto de vista quantitativo e qualitativo, a desoneração de receitas vinculadas. A primeira das inovações refere-se ao percentual de desvinculação, aumentando-se de $20 \%$ (vinte por cento) para 30\% (trinta por cento), um acréscimo significativo que representará uma expressiva ampliação nos valores dispostos de livre alocação, agora com maior percentual de incidência. A segunda grande alteração diz respeito ao prazo de vigência, uma vez que nas prorrogações anteriores estipulava-se normalmente um ciclo quadrienal de validade da DRU, ficando esta, agora, com vigência exageradamente dilatada, duplicando-se o período normal de prorrogação que sempre foi estipulado, favorecendo a renovação para uma validade de 8 anos, findando somente no exercício de 2023. Outra inovação importante é a permissão para a desvinculação da arrecadação das taxas federais, o que não ocorria no antes. Por fim, mais uma modificação, 
não menos impactante, refere-se à instituição expressa da Desvinculação das Receitas para os demais entes da federação, deixando de ser previsão exclusiva para a União, haja vista a inovadora inclusão dos Arts. 76-A e 76-B, com a desvinculação das receitas, respectivamente, em nível estadual e municipal.

A rigor, percebe-se, portanto, um fortalecimento do instituto de desvinculação das receitas, que deixa de ser temporário e torna-se um mecanismo permanente, com impacto orçamentário cada vez maior. Na verdade, trata-se de contorno às recomendações previstas na Carta Magna, por meio de manobra realizada objetivando dar uma folga maior de flexibilidade à alocação aos recursos públicos. A fórmula adotada tentar driblar a crescente tendência de rigidez orçamentária. O ideal, incontestavelmente, seria realizar uma ampla reforma fiscal de modo a revisar o sistema de vinculações. A realização de uma reforma, porém, não seria tarefa das mais fáceis, ao contrário, demandaria alterações complexas nos dispositivos constitucionais e exigiria negociações que, certamente, incitariam a oposição política. Ao se buscar prorrogar novamente a DRU, na incansável tentativa de flexibilização orçamentária e maior nível de recursos livres, opta-se, mais uma vez, pela saída mais cômoda, porém, de menor eficiência e transparência. E assim continuamos, ad eterno, com o esdrúxulo mecanismo de desvinculação de receitas. Até quando se darão suas repetitivas prorrogações?

\begin{abstract}
Adotada a sistemática das desvinculações, um efeito perverso é atingido: os recursos abrangidos pelas normas desvinculadoras deixam de ter a sua destinação submetida ao crivo do Congresso Nacional. Sem o controle parlamentar da destinação dos recursos, a gestão orçamentária torna-se menos democrática e um dos mecanismos de freios e contrapesos estabelecidos constitucionalmente vê-se severamente atingido. Não se trata, com efeito, de afirmar que o Poder Executivo aplica mal os recursos desvinculados. [...] Nesse sentido, a DRU desvia-se do modelo constitucional desenhado para a aprovação dos gastos públicos. Não se trata de uma inconstitucionalidade, pois o art. 76 do ADCT não tem o condão de ameaçar de abolição a separação entre os Poderes. Mas não se pode negar que se trata de um mecanismo com forte conotação antidemocrática, que afasta uma forma de controle de atuação do Poder Executivo. (CATAPANI, 2011, p. 263-264).
\end{abstract}

O mecanismo da DRU é espécie anômala ao ordenamento jurídico brasileiro, que escapa aos reais objetivos e princípios constitucionais. Trata-se de obra do famoso "jeitinho brasileiro", conhecido aliado dos grupos de poder, tão sutilmente aplicado à política brasileira e que, novamente, teima em entrar em cena. Em que pese as consideráveis razões acerca da necessidade de sua implantação, tal mecanismo não se sustenta do ponto de vista jurídico, a não ser que se entenda a Constituição Federal e o Ato das Disposições Constitucionais Transitórias como uma concha de retalhos, manipulável a qualquer momento. O instrumento 
orçamentário e, portanto, a aplicação dos recursos públicos, ainda não teve o olhar que merece por parte do poder público. Ao contrário, manobras de flexibilização e disputa de poder continuam intensas, frustrando o real objetivo do constituinte originário. E mais, emendas à Lei Maior, como o caso da Desvinculação das Receitas da União, acabam revelando uma conotação muito mais política e crise entre os poderes no âmbito das finanças públicas, longe de situar o debate na otimização das políticas públicas e no uso responsável dos recursos públicos. Ao fim e ao cabo, para quem é ineficiente no gasto, sempre faltarão recursos.

A propósito, com frequência, costuma-se alegar como argumento da necessidade de maior flexibilização e disponibilização de recursos a costumeira invocação da reserva do possível, em flagrante desrespeito aos ditames constitucionais aos quais se encontra adstrita a emanação de todo e qualquer poder ${ }^{26}$. É importante lembrar, neste ponto, que a legitimidade das políticas públicas adotadas pelo Estado está diretamente associada aos fins constitucionais que devem ser perseguidos em caráter prioritário. A reserva do possível não se configura em justificativa suficientemente escusável para que o Estado se exima de cumprir as suas precípuas funções. A rigor, embora o custo dos direitos e a limitação de recursos seja condicionante real e existente, tal limite, sob a roupagem aparentemente lícita da escassez de recursos, nem sempre estaria tão próximo como se induz, não houvesse a crônica deficiência na gestão dos recursos no âmbito das finanças públicas ${ }^{27}$.

26 Pela clareza e lucidez, vale rememorar trecho do voto do Exmo. Min. Celso de Mello, quando do julgamento da ADPF 45-DF no âmbito da Suprema Corte: "[...] a realização dos direitos econômicos, sociais e culturais além de caracterizar-se pela gradualidade de seu processo de concretização - depende, em grande medida, de um inescapável vínculo financeiro subordinado às possibilidades orçamentárias do Estado, de tal modo que, comprovada, objetivamente, a incapacidade econômico-financeira da pessoa estatal, desta não se poderá razoavelmente exigir, considerada a limitação material referida, a imediata efetivação do comando fundado no texto da Carta Política. Não se mostrará lícito, no entanto, ao Poder Público, em tal hipótese - mediante indevida manipulação de sua atividade financeira e/ou político-administrativa - criar obstáculo artificial que revele o ilegítimo, arbitrário e censurável propósito de fraudar, de frustrar e de inviabilizar o estabelecimento e a preservação, em favor da pessoa e dos cidadãos, de condições materiais mínimas de existência. Cumpre advertir, desse modo, que a cláusula da "reserva do possível" - ressalvada a ocorrência de justo motivo objetivamente aferível - não pode ser invocada, pelo Estado, com a finalidade de exonerar-se do cumprimento de suas obrigações constitucionais, notadamente quando, dessa conduta governamental negativa, puder resultar nulificação ou, até mesmo, aniquilação de direitos constitucionais impregnados de um sentido de essencial fundamentalidade”. (ADPF 45-DF, Min. Celso de Mello, DJ 04/05/2004, STF)

27 "Como se dá conta a problemática posta pelo "custo dos direitos", por sua vez, indissociável da assim designada "reserva do possível" (que, consoante já visto, não pode servir de barreira intransponível à realização dos direitos a prestações sociais), a crise de efetividade vivenciada com cada vez mais agudeza pelos direitos fundamentais de todas as dimensões está diretamente conectada com a maior ou menor carência de recursos disponíveis para o atendimento das demandas em termos de políticas sociais. Com efeito, quanto mais diminuta a disponibilidade de recursos, mais se impõe uma deliberação responsável a 
[...] também resta abrangida na obrigação de todos os órgãos estatais e agentes políticos a tarefa de maximizar os recursos e minimizar o impacto da reserva do possível. Isso significa, em primeira linha, que se a reserva do possível há de ser encarada com reservas, também é certo que as limitações da reserva do possível não são, em si mesmas, uma falácia, como já se disse mais de uma vez entre nós. O que tem sido, de fato, falaciosa, é a forma pela qual muitas vezes a reserva do possível tem sido utilizada entre nós como argumento impeditivo da intervenção judicial e desculpa genérica para a omissão estatal no campo da efetivação de direitos fundamentais, especialmente de cunho social. Assim, levar a sério a "reserva do possível" (e ela também deve ser levada a sério, embora sempre com as devidas reservas), significa também, especialmente em face do sentido do disposto no art. $5^{\circ}$, $\S 1^{\circ}$, da $\mathrm{CF}$, que cabe ao poder público o ônus da comprovação efetiva da indisponibilidade total ou parcial de recursos do não desperdício dos recursos existentes, assim como da eficiente aplicação dos mesmos. (SARLET, 2015, p. 293)

Por todo esse contexto, chega-se à irrefutável evidência da necessidade de vinculação dos órgãos estatais no que diz respeito à execução do orçamento público, o que reclama maior responsabilidade na gestão da peça orçamentária, sobretudo tendo em vista o contemporâneo processo de constitucionalização das finanças públicas. Aos poderes constituídos impõe-se o dever de fidelidade às opções do constituinte, as quais sempre serão limites à liberdade do legislador e discricionariedade do administrador, notadamente quando se cuida de gerenciar a escassez de recursos e otimizar a efetividade dos direitos. Apenas assim deslocaremos a noção da escassez dos recursos no sentido de que não resultem em obstacularização arbitrária à concretização dos direitos fundamentais, ou ainda, desvirtuamento arbitrário na utilização dos recursos públicos pela ampla liberdade gerada ao se desvincular receitas orçamentárias.

Ressalte-se, ainda, que a DRU impacta consideravelmente nas contribuições sociais, instituídas, fundamentalmente, para financiar a seguridade social, as quais, inequívoca e objetivamente, vinculam o emprego e a destinação de seus recursos arrecadados nos fins que motivaram a sua criação, ou seja, na realização dos direitos sociais a ela intrínsecos. São direitos públicos subjetivos dos indivíduos, universalizados e assumidos como dever intrínseco ao Estado, que conformam e se confundem com a dignidade de sua pessoa. Sendo assim, não incorporam qualquer concepção de margem de discricionariedade, pois está dentro do âmbito da obrigatoriedade do Estado de agir. O mesmo se diga, a propósito, a respeito das verbas destinadas à educação, também impactadas pelo mecanismo de desvinculação das receitas. Trata-se, assim, em última instância, de abrandamento de preceito constitucional. $\mathrm{Ou}$

respeito de sua destinação, o que nos remete diretamente à necessidade de buscarmos o aprimoramento de mecanismos de gestão democrática do orçamento público, assim como o próprio processo de administração das políticas públicas em geral, seja no plano da atuação do legislador, seja na esfera administrativa [...]." (SARLET, 2015, p. 370-371). 
seja, em proveito da existência de recursos livres para serem utilizados conforme as prioridades de governo, ignoram-se as prioridades constitucionais.

É bem verdade que as necessidades públicas são dinâmicas, flutuam no tempo, razão pela qual engessar a aplicação das despesas a setores pré-estabelecidos, sem maior folga para otimização gerencial, é tema preocupante e que merece reflexão ${ }^{28}$. A administração financeira e orçamentária do governo federal fica, indubitavelmente, mais comprometida sem os recursos provenientes da DRU. Contudo, os fins não justificam os meios. Não pode a União valer-se de manobra anômala como artifício para minguar a afetação dos recursos públicos e obter a livre alocação de receitas à revelia dos preceitos constitucionais. O que garante, por exemplo, que eventual futura emenda constitucional não venha aumentar o percentual da DRU para $40 \%$ (quarenta por cento), ou ainda, para $50 \%$ (cinquenta por cento)? O que garante que não venha haver nova prorrogação prolongando a validade até 2030, ou então, vire um instituto permanente (como, de fato, já tem sido)? Como garantir que nova alteração não abra espaço para incluir no cálculo da DRU outra parcela de receita vinculada? O que poderemos ter em um futuro breve, inexistindo segurança jurídica a impedir eventuais manobras que frustrem a real destinação constitucional orçamentária? Não raro, percebem-se forças políticas e econômicas, internas e externas, atuantes e sobrepostas à valores constitucionalmente idealizados. A Desvinculação de Receitas da União é, pois, mais um típico exemplo dessa realidade que urge ser repensada.

28 Conforme dados extraídos a partir do Parecer do Senado Federal no 706, de 2016, Relator Senador José Maranhão, o Demonstrativo da DRU, constante da Relação das Informações Complementares ao Projeto de Lei Orçamentária de 2016, contém a informação de que a desvinculação das contribuições sociais seria de R\$ 110,9 bilhões, a das contribuições de intervenção no domínio conômico seria de R \$ 4,6 bilhões e a das taxas seria de R \$ 2,2 bilhões. No total, a desvinculação atingiria R \$ 117,7 bilhões somente no exercício financeiro de 2016, representando significativo impacto nas contas do governo para fins de cumprimento das metas. Parecer disponível em http://www.senado.leg.br/atividade/rotinas/materia/getPDF.asp?t=197549\&tp=1>. Acesso em 12/set/2016. 


\section{5 - CONCLUSÃO}

O orçamento público, atualmente, necessariamente passa a ser percebido dentro de uma visão constitucional democrática, à luz da concretização dos direitos fundamentais. Torna-se imperioso, desse modo, que a sua gestão e consequente aplicação dos recursos públicos se adeque aos preceitos constitucionais, não se fazendo possível sua manipulação a pretexto de interesses que não dizem respeito com o seu real mister. A partir dessa evidência, ganha relevo a discussão quanto à flexibilização do orçamento público, de modo que este não se torne mera peça fictícia maneja ao sabor das vontades políticas. Ainda hoje existem mecanismos que acabam por frustrar a expectativa inicial estabelecida na lei orçamentária, instaurando-se uma efetiva crise no âmbito das finanças públicas no Brasil.

Nesse contexto, enfocamos neste ensaio o estudo da Desvinculação das Receitas da União (DRU), mecanismo que se arrasta desde 1994 e, agora, novamente teve sua validade prorrogada até o ano de 2023 pela Emenda Constitucional nº 93/2016. A DRU surge com o objetivo de ampliar os recursos livres da União, dando maior margem de liberdade ao gestor para eleição das áreas de alocação prioritárias. Contudo, a fórmula adotada trata-se, a rigor, de nítida tentativa de driblar a crescente tendência de rigidez do orçamento. Incontestavelmente, o ideal seria a realização de uma ampla reforma fiscal. Ao se prorrogar novamente a DRU, na incansável busca pela flexibilização orçamentária e maior nível de recursos livres, optou-se, mais uma vez, pela saída mais cômoda, porém, de menor segurança jurídica e transparência. 


\section{REFERÊNCIAS}

ABRAHAM, Marcus. Efetividade e vinculação das leis orçamentárias e a ADI 4.663. In GOMES, Marcus; ABRAHAM, Marcus; TORRES, Heleno Taveira (coords). Direito financeiro na jurisprudência do Supremo Tribunal Federal: homenagem ao ministro Marco Aurélio. Curitiba: Juruá, 2016.

BARCELlOS, Ana Paula de. A Eficácia Jurídica dos Princípios Constitucionais. Rio de Janeiro: Renovar, 2002.

BARROSO. Neoconstitucionalismo e constitucionalização do direito: o triunfo tardio do direito constitucional no Brasil. Revista da EMERJ, v. 9, n. 33, 2006.

BINENBOJIM, Gustavo. Uma teoria do direito administrativo: direitos fundamentais, democracia e constitucionalização. 3ed. Rio de Janeiro: Renovar, 2014.

CATAPANI, Marcio Ferro. A discricionariedade do Poder Executivo na elaboração do projeto de lei orçamentária anual. In: CONTI, José Maurício; SCAFF, Fernando Facury (Orgs.). Orçamentos Públicos e Direito Financeiro. São Paulo: Revista dos Tribunais, 2011, p. 263-264).

DALLARI, Adilson Abreu. Orçamento impositivo. In: CONTI, José Maurício; SCAFF, Fernando Facury (Orgs.). Orçamentos Públicos e Direito Financeiro. São Paulo: Revista dos Tribunais, 2011.

DALLAVERDE, Alexsandra Katia. As relações entre os poderes na gestão das finanças públicas. Porto Alegre: Nuria Fabris, 2013.

FARIA, José Eduardo. O Direito na Economia Globalizada. São Paulo: Malheiros, 1999.

FERRAJOLI, Luigi. A democracia através dos direitos: o constitucionalismo garantista como modelo teórico e como projeto político. São Paulo: Revista dos Tribunais, 2015.

FREITAS, Juarez. O direito fundamental à boa administração pública. São Paulo: Malheiros, 2014.

FUX, Luiz. Orçamento público na jurisprudência do STF: a possibilidade de controle judicial, a autonomia constitucional orçamentária e a problemática do orçamento participativo. In GOMES, Marcus; ABRAHAM, Marcus; TORRES, Heleno Taveira (coords). Direito financeiro na jurisprudência do Supremo Tribunal Federal: homenagem ao ministro Marco Aurélio. Curitiba: Juruá, 2016.

HESSE, Konrad. A força normativa da constituição. Tradução de Gilmar Ferreira Mendes. Porto Alegre: Sérgio Antônio Fabris, 1991. 
MENDONÇA, Eduardo Bastos de. A constitucionalização das finanças públicas no Brasil: devido processo orçamentário e democracia. Rio de Janeiro: Renovar, 2010.

Da faculdade de gastar ao dever de agir: o esvaziamento contramajoritário de políticas públicas; In SARLET, Ingo Wolfgang; TIMM, Luciano Benetti (Orgs.). Direitos Fundamentais, orçamento e reserva do possível. 2 ed. Porto Alegre: Livraria do Advogado, 2013.

SARLET, Ingo Wolfgang. A eficácia dos direitos fundamentais: uma teoria geral dos direitos fundamentais na perspectiva constitucional. 12ed. Porto Alegra: Livraria do Advogado, 2015. SARMENTO, Daniel. Constituição e globalização: a crise dos paradigmas do direito constitucional. Revista de Direito Administrativo, v. 215, p. 19-34, 1999.

- Ubiquidade constitucional: os dois lados da moeda. Revista de Direito do Estado, no 2, p. 83-118, 2006.

STELZER, Joana. O fenômeno da transnacionalização da dimensão jurídica, in STELZER, Joana; CRUZ, Paulo Márcio. Direito e Transnacionalidade. Curitiba: Juruá, 2009.

TORRES, Heleno Taveira. Direito constitucional financeiro: teoria da constituição financeira. São Paulo: Revista dos Tribunais, 2014.

TORRES, Ricardo Lobo. Tratado de Direito Constitucional Financeiro e Tributário: orçamento na Constituição. 3 ed. Rio de Janeiro: Renovar, 2008, v.5. 